\title{
ADVANCING LOW EMISSION GROWTH IN THE PHILIPPINES
}

Windy coastlines of island nations are often well-suited for wind farms like the North Wind Bangui Bay Project, located in Bangui, llocos Norte, in the northern Philippines. Through EC-LEDS support, the Philippines is updating wind resource maps at 80 -meter hub height to support deployment of new wind power projects across the country.

PHOTO FROM ISTOCK 1433455
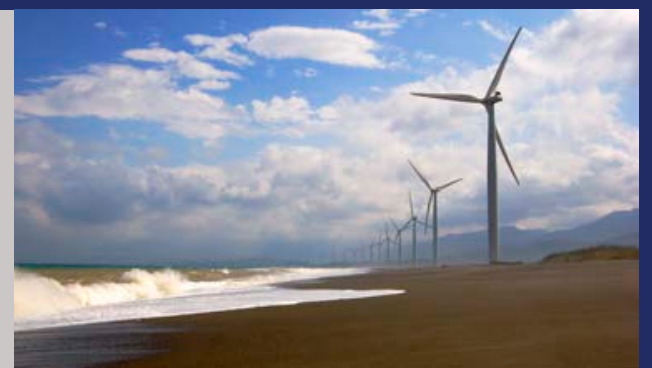

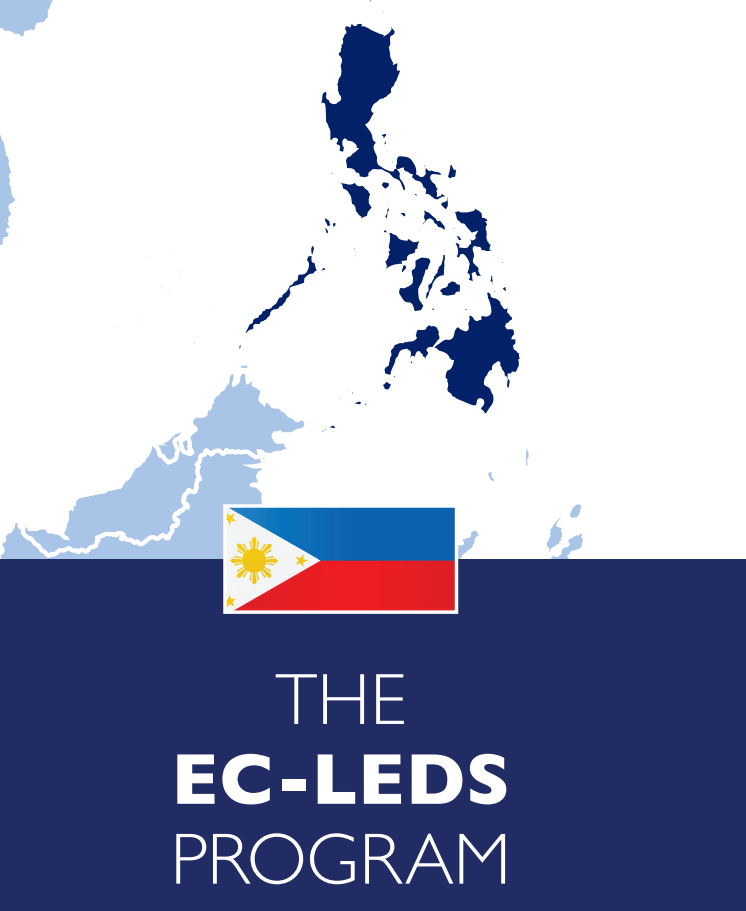

The Philippines, an island nation of nearly 100 million people and one of the world's I 5 most populous nations, is grappling with the challenge of expanding economic opportunities for its people. At the same time, it is one of the nations at greatest risk from climate change impacts, including rising

QUICK FACT: If not addressed, energy sector emissions are forecast to quadruple and transport sector emissions are expected to double by 2030 . sea levels and more frequent and intense floods and storms.

Recognizing that addressing climate change is critical to its future, the Philippines is working to lower emissions even as

its economy grows. To meet that objective, the country has outlined its low emission development strategy (LEDS) in key documents, such as the National Climate Change Action Plan and the Philippine Development Plan.

Through the Enhancing Capacity for Low Emission Development Strategies (EC-LEDS) program, the Philippines is partnering with the United States to help quicken the continued development and acceleration of its LEDS. The technical assistance enables the Philippines to better integrate low emission growth into long-term planning and implement key actions.

The Philippines Climate Change Commission - the coordinating body for low emission planning and sustainable development-is collaborating with EC-LEDS to:

- Build and strengthen the Philippines's national greenhouse gas (GHG) emissions inventory

- Develop and improve data and analysis capabilities, which are used as the basis for low emission development planning

- Promote large-scale deployment of clean energy technologies, and reduce GHG emissions from deforestation and land-use changes.

"Getting a grip ... on climate change in the Philippines: Overview." Washington, D.C.:World Bank, 2013.

Low emission development strategies (LEDS) are development plans that promote sustainable social and economic development while reducing greenhouse gas emissions over the medium to long term.

Enhancing Capacity for Low Emission Development Strategies (EC-LEDS) is a flagship U.S. government-led effort that assists countries in developing and implementing LEDS. The program enhances partner country efforts by (I) providing targeted technical assistance and (2) building a shared global knowledge base on LEDS.

\section{EC-LEDS country partners} include Albania, Bangladesh, Cambodia, Colombia, Costa Rica, Gabon, Georgia, Guatemala, Indonesia, Jamaica, Kazakhstan, Kenya, Macedonia, Malawi, Mexico, Moldova, Peru, the Philippines, Serbia, South Africa, Thailand, Ukraine, Vietnam, and Zambia. 


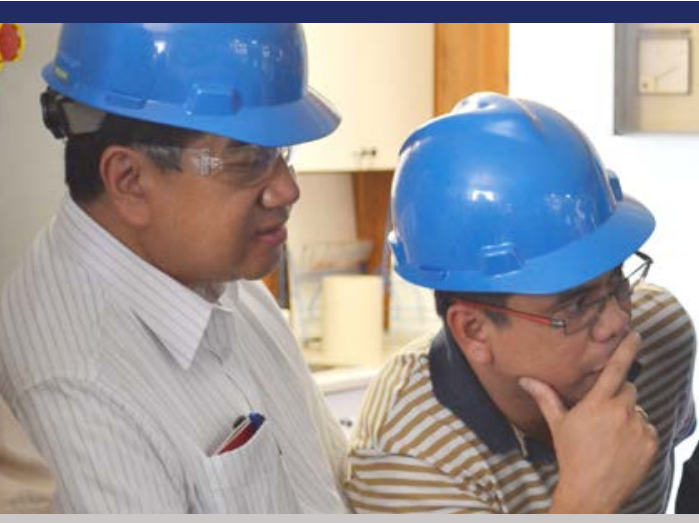

Senior delegates from the Philippines government examine combined heat and power equipment at a wood mill facility during a field visit near Sacramento, California. Biomass is a plentiful resource in the Philippines, and this particular plant demonstrates LEDS themes in that sector.

PHOTO BY DAN BILELLO, NREL 26953

\section{SUPPORTING THE PHILIPPINES'S LEDS PRIORITIES}

EC-LEDS assistance is targeted to a country's needs. Two examples of working areas within the EC-LEDS-Philippines partnership are deploying clean energy and improving forest management.

\section{DEPLOYING CLEAN ENERGY}

In the Philippines, deploying clean energy is one key way to improve energy access, increase energy security, and address climate change.

Thus, EC-LEDS is partnering with the Philippines to provide training and technical support for a low emission energy sector.

\section{Joint activities include:}

- Conducting grid impact analyses to help overcome the hurdles to integrating renewable energy into the power grid
- Developing tools and maps to assess the siting of renewable energy equipment, helping private investors maximize their investment

- Evaluating alternative transportation options to reduce the environmental impacts of transportation

- Modeling energy and economic scenarios for national climate change and development planning, ensuring future energy needs are met in low emission ways

- Analyzing the renewable energy market (e.g., costs, electric rates, and competition) to identify possible financing opportunities.

\section{IMPROVING FORESTRY AND LAND-USE PLANNING}

Improved forest management is a vital component of the country's strategy to reduce $\mathrm{GHG}$ emissions from landuse changes. EC-LEDS is helping the Philippines improve the design and implementation of forestry programs with climate benefits.

\section{EC-LEDS activities include:}

- Building expertise in collecting, processing, and archiving GHG inventory data, providing a foundation for managing and monitoring land-use emissions

- Training specialists in forest cover mapping using remote-sensing technologies, and creating a national forest inventory designed to support improved forest data accuracy and availability for forest management decision-making

- Supporting analytically based forest-use land planning to ensure the sustainable use of available resources, maximizing environmental and climate benefits.
For more information:

Joseph Foltz

USAID/Philippines

$+\mid-632-30$ |-603|

jofoltz@usaid.gov
Alexia Kelly
U.S. Department of State Office of Global Change + - -202-53|-7466 kellyac@state.gov
Collin Green
USAID Office of Global
Climate Change
|-202-7| 2-4505
cgreen@usaid.gov

EC-LEDS ACCOMPLISHMENTS

IN THE PHILIPPINES

Several notable accomplishments have been achieved through the EC-LEDS program:

Developed methods to facilitate GHG data inputs across government agencies. As a result, the Philippines will formalize an executive order that defines the institutional arrangements for a national GHG inventory system, which is vital for identifying sources of current emissions and low emission development planning.

Increased use of analytical tools for LEDS planning. EC-LEDS trained 29 technical experts to identify and prioritize energy options using the Long range Energy Alternatives Planning (LEAP) system, which will be incorporated into the country's energy plan. Another 35 in-country transportation specialists were trained to analyze sustainable transport and fuel alternatives.

Supported capacity building in forest monitoring and forest land-use planning. Fifty-five Filipino experts received technical training on forest monitoring using both remote sensing and ground inventory data. Another 148 forest sector stakeholders were trained on analytically based forest landuse planning using geographic information systems and environmental assessment tools.

\section{Strengthened integrated clean} energy planning. Tools like the Geospatial Toolkit were used for clean energy technology deployment planning on both the regional and local levels, including within specific government units such as Siargao Island.
EC-LEDS is managed by the U.S. Agency for International Development (USAID) and U.S. Department of State with support from the U.S. Department of Energy, U.S. Environmental Protection Agency, U.S. Department of Agriculture, and U.S. Forest Service.
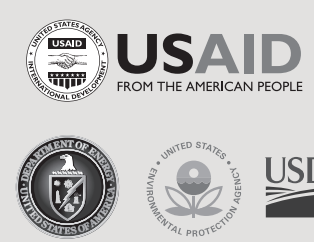

\section{ec-leds.org}

Printed with a renewable-source ink on paper containing at least 50\% wastepaper, including 10\% post consumer waste.
EC-LEDS

ENHANCING CAPACITY FOR LOW EMISSION DEVELOPMENT STRATEGIES
NREL/FS-7A40-60176 November 2013 